\title{
Le théâtre de la Foire. Des tréteaux aux boulevards.
}

\section{Philippe Bourdin}

\section{(2) OpenEdition}

\section{Journals}

Édition électronique

URL : https://journals.openedition.org/ahrf/1550

DOI : 10.4000/ahrf.1550

ISSN : 1952-403X

Éditeur :

Armand Colin, Société des études robespierristes

Édition imprimée

Date de publication : 1 septembre 2004

Pagination : 201-202

ISSN : 0003-4436

\section{Référence électronique}

Philippe Bourdin, «Le théâtre de la Foire. Des tréteaux aux boulevards. ». Annales historiques de la Révolution française [En ligne], 337 | juillet-septembre 2004, mis en ligne le 15 février 2006, consulté le 23 avril 2022. URL : http://journals.openedition.org/ahrf/1550 ; DOI : https://doi.org/10.4000/ahrf. 1550

Ce document a été généré automatiquement le 23 avril 2022

Tous droits réservés 


\title{
Le théâtre de la Foire. Des tréteaux aux boulevards.
}

\author{
Philippe Bourdin
}

\section{RÉFÉRENCE}

Isabelle Martin, Le théâtre de la Foire. Des tréteaux aux boulevards, Oxford, Voltaire Foundation, 2002, 385 p., ISBN 0-7294-0797-7.

1 On connaît les nombreux travaux de David Trott sur le théâtre de Foire. I. Martin s'essaie à son tour à une synthèse non seulement sur le répertoire (1 133 titres sont cités en annexe, tandis que Trott n'en relevait "que" 873) mais aussi sur les conditions matérielles de production, les mises en scène et les acteurs. L'auteur a travaillé notamment à partir de quinze fonds de la Bibliothèque nationale, de la série $\mathrm{K}$ des Archives nationales, des archives de la Comédie-Française et de l'Opéra. Elle aborde dans une première partie les conditions d'une genèse (les foires, les loges, la concurrence entre théâtres, les problèmes d'argent, les auteurs, avec le cas particulier de Lesage), dans une seconde partie la gestation d'une forme littéraire (les techniques théatrales, les sujets et les thèmes, les personnages), le tout pour une période courant de la fin du XVIIe siècle aux années 1760, époque de migration des théâtres de la foire vers les boulevards, «dans une architecture de plus en plus décorative et luxueuse des salles, destinées à un répertoire de plus en plus complexe dont l'effet sera de retenir les riches mais aussi d'écarter les classes inférieures »- à la même époque, les parades des salons récupèrent une partie de la vulgarité ici abandonnée (p. 17).

2 Le monde de la "bâtardise » joue avant tout sur le visuel et le rire, saisonnier de foire en foire, sans subventions, sans salles officielles, le plus souvent sans le relais de la librairie. Seul le succès de la pièce assure sa relative pérennité, sa publication éventuelle ne reproduisant qu'un texte expurgé pour satisfaire la censure royale: comparant les différences entre les manuscrits et les imprimés de Lesage, peut-on uniquement conclure à sa volonté de faire de l'opéra-comique une arme de réforme 
morale débarrassée de sa gangue rabelaisienne ? Usant de la pantomime, de l'acrobatie, des monologues, des tableaux, de l'improvisation, des marionnettes et de chants populaires, satirique et moraliste, le théâtre de Foire prend sa source dans l'actualité (la faillite de Law suscitera plusieurs textes sur le bon usage de l'argent), dans les emprunts aux auteurs classiques (la tragédie grecque, la commedia dell'arte, Molière, La Fontaine) comme dans les mythes populaires et aristocratiques, remontant souvent au Moyen Âge - rois sacrifiés, forêts magiques, fontaines miraculeuses, dragons hantent les tréteaux où l'exotisme est volontiers accueilli. Le tout pour mieux dessiner, au-delà des inévitables intrigues amoureuses dans lesquelles se glissent Arlequin, Scaramouche, Pierrot, Mezzetin, Polichinelle, Léandre, Pantalon ou Colombine, un monde manichéen et volontiers allégorique, dénoncer les privilèges, le jeu, défendre une certaine homogamie sociale dans le mariage, et exalter les vertus du travail, de l'honnêteté, de l'égalité devant la loi, selon une morale qui doit rarement au christianisme et marque au contraire une laïcisation des esprits.

3 L'habileté des entrepreneurs, se livrant entre eux à une concurrence féroce, à mobiliser des capitaux et à profiter de la vogue de ce style de divertissement, qu'ils contribuent à entretenir au détriment des grandes institutions privilégiées, est notable. D'où les pressions de la Comédie-Française pour faire interdire la concurrence, avec succès en 1719-1720 et entre 1745 et 1751, grâce au soutien du Parlement de Paris, non ensuite. Car il faut compter aussi avec les protecteurs du théâtre de Foire: l'Archevêché de Paris, soucieux des revenus pécuniaires des foires, relevant du domaine ecclésiastique, l'administration et la magistrature dont sont issus plusieurs auteurs - la plupart, au demeurant, préférant protéger leur réputation derrière l'anonymat -, voire la Cour, qui n'hésitera pas pour ses amusements à inviter plusieurs troupes à Versailles, sans compter un public divers (du noble à l'étudiant en passant par l'artisan ou le voleur à la tire) qui finit par faire sienne la lutte contre les privilèges - naissance d'une opinion publique qui aurait dû être mieux mise en perspective comme l'auteur aurait pu se soucier davantage de l'influence des spectateurs sur le contenu du répertoire.

4 I. Martin produit avec modestie un ouvrage très riche en informations. On appréciera notamment sa description matérielle des tréteaux forains, son analyse des fluctuations de la production, en crise à partir des années 1750 , son étude de la sociologie des auteurs divers et prolixes. Hommes de lettres installés, peintres ou musiciens Rameau, Boucher, Servandoni-, professionnels de la scène, jusqu'aux membres des professions libérales, artisans, religieux même, tous ne laissent qu'un strapontin aux rares femmes qui se risquent à l'écriture, telle Mme Favart; beaucoup apprécient de travailler en équipe dans les cafés, les auberges, les salons. Privilégiant la première moitié du XVIIIe siècle et notamment le "règne" de Lesage, l'auteur arrête ostensiblement son enquête en 1789, année de la suppression de la foire Saint-Laurent. Le spécialiste de la Révolution devra donc s'en remettre aux travaux de D. Trott qui a montré combien le théâtre de Foire ne s'éteint jamais complètement: parce que des entrepreneurs célèbres comme Nicolet (du Théâtre des Grands Danseurs) ou Audinot (de l'Ambigu Comique) continuent à gérer plusieurs lieux, et en l'occurrence les vestiges de leurs anciennes installations de la foire Saint-Germain ; parce que seize des vingt-deux artistes à succès des années 1780 restent à l'affiche sous la Révolution, dont Sedaine, Anseaulme, Vadé ; parce que le "genre ", si le mot convient pour une forme d'art qui n'est qu'amalgame et liberté, au-delà de ce répertoire, inspire l'écriture 
théâtrale dans laquelle on retrouve des segments, tels que les compliments de clôture, qui en sont hérités, ou l'improvisation des calembours et des bons mots. 